\title{
RESENHA
}

\section{"SEGREDOS DE WALT DISNEY: HISTÓRIAS INÉDITAS, NÃO OFICIAIS, SEM CENSURA E NÃO AUTORIZADAS SOBRE O REINO MÁGICO”, DE JIM KORKIS.}

Tiago Zaidan

Em 17 de junho de 1955, uma benção proferida pelo reverendo Glenn Puder, testemunhada por representantes religiosos católicos, judaicos e protestantes, inaugurou a Disneylândia (KORKIS, 2015, p. 50), espaço de entretenimento e consumo o qual alçou os parques ao patamar de parques temáticos (conceito inédito à época) - empreendimentos altamente lucrativos que simulavam um reino à parte, com histórias retiradas das produções levadas à luz pela própria Disney (ASHTON, 2003, p. 122).

Dias antes, na tarde-noite de 13 de julho, o parque teve sua última prova, antes de receber as famílias americanas sedentas por lazer. 300 convidados foram conduzidos por atrações específicas da Disneylândia, como o barco a vapor Mark Twain, o qual navegou pelo canal artificial, batizado de Rios da América, até um grande restaurante temático - com palco, camarote e lustres bem trabalhados -, o Golden Horseshoe Saloon, tudo a pretexto do trigésimo aniversário de casamento de Walt (1901-1966) e Lillian "Lilly" Disney (1899-1997) (KORKIS, 2015, p. 59; 61).

Antes da comemoração, o anfitrião havia passado o dia inspecionando o parque - talvez, mais uma obsessão que um sonho. Além da poeira, típica em construções recentes, ainda havia grama e árvores a plantar. À noite, durante o festejo, na embarcação iluminada e adornada, tudo estava saindo como planejado. No restaurante, além do jantar, um espetáculo fora providenciado, com uma trupe que incluía o comediante Wally Boag (1920-2011), o qual encerrava a sua participação sacando pistolas reluzentes as quais borrifavam água na platéia (KORKIS, 2015, p. 60; $62)$.

No entanto, nada chamou mais atenção naquela prévia da Disneylândia - em que foram servidos drinks à vontade - que o próprio Walt, cuja atitude é relatada por sua filha, Diane Disney (1933-2013):

[...] de repente o vimos pendurado no balcão tentando pular no palco. [...]. Pensei que ele fosse cair do balcão, mas ele conseguiu descer até o palco. Ficou parado ali, sorrindo. [...]. Então a mamãe se levantou e foi até as escadas para subir ao palco, pensando: 'se eu subir lá talvez consiga trazer o Walt de volta'. Só que isso não aconteceu. [...]. Meu pai ficou firmemente plantado ali, só aproveitando aquele momento, adorando cada minuto dele. Acho que alguém deve ter percebido nossa frustração porque a banda começou a tocar, e Edgar Bergen subiu ao palco e começou a dançar comigo. [...]. Todos começaram a dançar e meu pai foi delicadamente empurrado para os bastidores (KORKIS, 2015, p. 63).

Naquela noite, Diane precisou levar o pai para casa. No banco de trás do carro, Walt,

Enrolou seus projetos - acho que era um mapa da Disneylândia - e começou a tocar o tubo de papel como se fosse um trompete, no meu ouvido, feito um menininho com um instrumento de brinquedo. Então passou a cantar uma canção ou coisa assim. Quando fui ver, tudo ficou quieto. Olhei para o banco de trás e o vi sentado ali, como um menininho, com aquele instrumento improvisado nos braços, profundamente adormecido (KORKIS, 2015, p. 64).

O longo depoimento de uma das filhas de Walt é um dos vários testemunhos coletados e publicados pelo historiador da Disney, Jim Korkis, no livro Segredos de Walt Disney: histórias inéditas, não oficiais, sem censura e não autorizadas sobre o reino mágico. Apesar do título estridente e de a obra trazer, de fato, episódios pouco conhecidos, o livro passa longe de abordar temas proibidos, como sugere o seu marketing. Embora dê pistas do gênio centralizador de Walt em sua relação com os subordinados, Korkis não aborda a polêmica relação de Disney com os funcionários sindicalizados - sobretudo animadores do estúdio o qual produziu Branca de Neve e os Sete Anões. Sobre este assunto, recomenda-se a biografia Walt Disney - O príncipe Sombrio de Hollywood, do norte-americano Marc Eliot.

Mesmo a alcunha de "não autorizado", presente no título da obra resenhada, pode ser questionado, uma 
vez que a própria filha de Walt Disney, Diane, assina o prefácio do livro, além de se configurar numa das mais importantes fontes do autor. Diane chega a afirmar: "Jim não coloca meu pai num pedestal, mas sem dúvida gosta dele, o que, porém não influi, a meu ver, em sua capacidade de apresentar opiniões objetivas sobre ele" (KORKIS, 2015, p. 13).

Possivelmente o tema mais controverso abordado no livro de Korkis seja a ligação de Walt com o FBI como contato SAC (sigla para Agente Especial Encarregado) em tempos de guerra fria e caça as bruxas. Por "bruxas", leia-se: suspeitos de simpatizarem com o comunismo. Os contatos cognominados como SAC tratavam-se de "[...] pessoas confiáveis, que eram fontes de informação aceitáveis sobre uma indústria em particular ou uma área especializada" (KORKIS, 2015, p. 240).

Isto, no entanto, não impediu a torcida de Walt pela visita do então primeiro ministro soviético Nikita Khrushchev (1894-1971) à Disneylândia, durante a turbulenta passagem do líder russo pelos Estados Unidos em 1959. O produtor de cinema e idealizador do parque temático esperava obter boa dose de publicidade global para o seu empreendimento, inaugurado há apenas quatro anos (KORKIS, 2015, p.219). Khrushchev e a sua família haviam declarado o desejo de conhecer o parque na Califórnia - o que não deixa de ser uma ironia, tratando-se a Disney um inconteste símbolo do capitalismo mundial. A visita ao reino de Mickey Mouse, porém, foi embargada por motivo de segurança, frustrando os visitantes. Os ânimos estavam acirrados e a população norte-americana conservava forte sentimento antissoviético. Khrushchev teria demonstrado a sua insatisfação com a impossibilidade do passeio em algumas declarações, o que repercutiu na imprensa, contribuindo com a divulgação do parque de um jeito ou de outro (KORKIS, 2015, p. $216 ; 219)$.

Apesar das eventuais lacunas, deve-se reconhecer o mérito da investigação, quase obsessiva, de Korkis a assuntos relacionados à Disney. Sua metodologia abrange pesquisas em livros, muito dos quais obscurecidos pelo tempo, especialmente autobiografias de pessoas envolvidas com os episódios narrados; documentos diversos e, principalmente, depoimentos, os quais são, certamente, o carro-chefe da metodologia do autor. O resultado é espelhado nas diversas citações, as quais dão voz a personalidades diversas, que vão da filha de Disney a funcionários antigos da Disneylândia e do Walt Disney World.

Todo este trabalho, além de aguçar o encanto do autor pelo conglomerado de comunicação e entretenimento, o levou a uma conclusão: ao menos as memórias organizacionais não são tratadas como princesas no reino mágico de Mickey Mouse. "Fiquei chocado ao descobrir que alguns documentos haviam sido destruídos por economia nos custos de armazenagem ou porque uma atração havia sido desativada ou nunca tinha sido construída", revela Korkis (2015, p. 151), o qual já foi coordenador do Centro de Aprendizado Disney, onde pesquisava, escrevia e facilitava apresentações sobre a história corporativa da companhia para membros do público interno e parceiros (KORKIS, 2015, p. 287).

Se alguns documentos foram destruídos, outros tantos simplesmente sumiram. É provável que muitos tenham sido roubados. Alguns roteiros e esboços de desenhos de produções dos estúdios que acabaram não levadas a cabo seriam hoje verdadeiras preciosidades. Cite-se, por exemplo, os esboços do artista plástico espanhol Salvador Dali (1904-1989). O ícone do surrealismo e Walt firmaram uma parceria em 1946 para a produção de um segmento o qual deveria ter entre seis e oito minutos e combinar animação com atores reais. Dali frequentou o terceiro andar dos estúdios e trabalhou no projeto até este ser cancelado sob a vaga alegação de "mudança de política no plano de distribuição” (KORKIS, 2015, p. 99; 103). Apenas em 1958, Walt tomou conhecimento do sumiço de vários esboços de Dali, confeccionados no bojo da parceria e que deveriam estar no "arquivo morto". A partir de 1970, graças ao trabalho do arquivista Dave Smith, algumas peças foram recuperadas (KORKIS, 2015, p. 104).

Em contrapartida, o estúdio Disney ainda mantém em seus arquivos um argumento e um roteiro, escritos, sob encomenda, em meados da década de 1940, pelo escritor inglês Aldous Huxley (1894-1963), para a produção de um filme baseado nos personagens da obra Alice no País das Maravilhas, do romancista e matemático Lewis Carroll (1832-1898) (KORKIS, 2015, p. 111; 118).

Dali e Huxley são duas das personalidades emblemáticas da cultura mundial com as quais Walt procurou estabelecer contato. Surpreendentemente, Jim Korkis revela que Disney nunca fora um bom aluno. 
Talvez o hábito da leitura o tenha salvado. Sempre atrasado em dois anos com relação ao resto da turma, a única cerimônia de formatura da qual participou foi a de conclusão do ensino fundamental, em 8 de junho de 1917. Desde esta época já era conhecido como o menino que ia ser desenhista, o que nem sempre era bem visto (KORKIS, 2015, p. 38; 40).

Certa vez, em uma sala de aula da escola primária de Benton, em Kansas City, Missouri, um zeloso diretor deparou-se com Walt se dedicando a desenhar caricaturas no verso de um livro de geografia em vez de tomar a lição. Embora fosse tido como um "cara bacana", nas palavras do próprio menino desenhista, o diretor repreendeu o garoto com a frase: "Meu jovem, você nunca vai ser nada na vida" (KORKIS, 2015, p. 41). Não era a primeira vez que o estudante Walter fora admoestado no ambiente escolar por conta de sua mania de desenhar.

Antes, com apenas sete anos, na Escola de Ensino Fundamental Park, em Marceline, também no Missouri, a professora, além de tratá-lo pela alcunha de "o segundo mais burro da sala", queixava-se da concorrência com a confecção das caricaturas pela atenção do discente (KORKIS, 2015, p. 39-40). Em 1960, quando Walter já era Walt Disney, aquela mesma escola, em Marceline, foi rebatizada, em homenagem ao ilustre ex-discente. A bem da verdade, a velha Park fora apenas a terceira escola a receber o nome de Walt Disney. Antes dela, instituições de ensino em Levittown, Pensilvânia, e Anaheim, na Califórnia, concederam esta homenagem ao aluno pouco producente (KORKIS, 2015, p. 42).

Hoje, ironicamente, inúmeros colégios em todo o mundo, públicos e privados, levam o nome do produtor cinematográfico e pai de Mickey Mouse. Walt, também, não ficou sem títulos. Recebeu diversos diplomas honorários, inclusive de Mestre em Artes por Yale e Harvard (KORKIS, 2015, p. 39).

Mais do que revelar histórias curiosas, Segredo de Walt Disney é, ainda, um libelo à importância da memória organizacional, tema sobre o qual autores consagrados no Brasil, como Paulo Roberto Nassar de Oliveira, tem se dedicado com afinco, inclusive com livros publicados (vide a obra Relações públicas na construção da responsabilidade histórica e no resgate da memória institucional das organizações, de Nassar).

\section{Referências}

ASHTON, Mary Sandra Guerra. Parques temáticos: espaços e imaginário. In: GASTAL, Susana; CASTROGIOVANNI, Antonio Carlos (Orgs.). Turismo na pós-modernidade: (Des)inquietações. Porto Alegre: EDIPUCRS, 2003 (Col. Comunicação). p. 121-129.

KORKIS, Jim. Segredos de Walt Disney: histórias inéditas, não oficiais, sem censura e não autorizadas sobre o reino mágico. Tradução: Celina C. Falck-Cook. São Paulo: Seoman, 2015. p. 287.

Recebido em: 28 julho de 2015

Aceito em: 20 agosto 2015 